null • Business of Knowing

\title{
Hire Everyone: Scholarly Publishing and Cooperative Sustainability
}

Dan Rudmann, Kayshini Holbourne, Elli Gerakopoulou

Published on: Aug 16, 2021

DOI: $10.21428 / 6 \mathrm{ffd} 8432.72 \mathrm{cb} 6467$

License: Creative Commons Attribution 4.0 International License (CC-BY 4.0). 


\section{Compensating people for their efforts}

Scholarship is indelibly marked by the jobs crisis in higher education. The loss of opportunity, mobility, and freedom for academics shape what is researched, taught, and published. Precarity and casualization of employment are now the prevailing conditions of academic labor. While a complex network of factors have resulted in our present moment, we can also observe that academic institutions, who for decades touted their exclusion rates as marks of quality, have come to realize those logically adjacent effects of striving to leave people out.

As academic publishing evolves toward Open Access, creating new sites of knowledge sharing and production, the publishing community has an opportunity to learn from institutional academia so that we might develop more inclusive, sustainable practices. But what do we mean when we evoke sustainability? Too often the term is conflated with conservation, a kind of scaling back that asks scholars to do more, or maintain the status quo, with less. Notions of sustainability have lent their support to scarcity narratives that attempt to justify the current state of academia.

New sites of knowledge sharing can be truly sustainable if they sustain the people who occupy those spaces. The operation of such spaces must veer away from conservationfocused practices that have led to the devaluation of intellectual labor, the devaluation of critical and creative production. We must acknowledge that such production sustains us, individually and as communities, in profound and mundane ways. Only with such signification can we begin to approach meaningful transactions and exchanges toward a thriving industry for publishing.

If we are to recognize the complex and variegated significance of publishing knowledge, which might hopefully supplant current discourse on impact and concurrently acknowledge the consequence of such work for its laborers, it can no longer be acceptable that any element of this production might exist without remuneration. As we create new spaces for learning through Open Access, the age of indirect compensation covered by the institution, is long over. The practice of sustainable compensation must extend to every aspect of publishing, including composition, editing, and peer review.

The opening of spaces for scholarship necessitates a recognition that knowledge production is open to a multitude of forms. Expanding our vision of knowledge forms proliferates possibilities in who might participate in its production. Therefore, efforts 
to arrive at Open Access are more closely fulfilled by enacting welcoming and democratic sites for knowledge sharing. We must acknowledge that a significant amount of labor and number of laborers is necessary to maintain these spaces. This industry will be sustainable, therefore, through investment and infrastructure to sustain those people, communities, and forms of participation that enable scholarly publishing.

Academia's job crisis has resulted in the un- or under-employment of people highly invested, interested, and skilled in the production of scholarship. Cooperative organizing can counteract this trend by sharing power and ownership among those engaged in scholarly work. This structure can allow more people to guide the industry of academic publishing toward innovative spaces and polyphony, engendering greater participation. It is the generation of scholarship that results from sustaining more people that will in turn further sustain scholarly publishing. We must reject the impulse for efficiency in favor of a desire to flourish.

Therefore, it is not within the purview of this piece of writing to outline a solution for scholarly publishing. Instead, our work here is to advance a belief that there are many people - some working within the institution, some who persisted through graduate school and were unable to gain institutional employment afterwards, some who left graduate school realizing that it was no longer sustainable for them, some who never had the opportunity and privilege to participate in higher education but have the desire and will to share and develop knowledge, and many more - who themselves are solutions for scholarly publishing. The more pressing work at present, then, is to empower and sustain those people. Our contention is that developing cooperative organizations can sustain people and thereby result in a multiplicity of pathways to generate the industry of publishing.

\section{Introducing coops to knowledge production}

The cooperative model is envisioned in this proposal as a way of rethinking Open Access scholarly publishing as a means to encourage horizontal, diverse, and plural decision making and ownership. A coop is an enterprise or organisation that is owned and managed by its members for the purpose of meeting their common needs (https://www.uk.coop/understanding-co-ops/what-co-op). According to the International Cooperative Alliance (ICA), cooperatives are driven by the following ideals and principles: 
- voluntary membership

- democratic member control

- member economic participation

- autonomy and independence

- education, training, and information

- cooperation among cooperatives

- concern for community

Following cooperative values in Open Access knowledge production and dissemination could lead to sustainable and fair publishing as well as alternative, diverse, and multidimensional knowledges $\underline{1}$. The cooperative model is concerned with fostering and nurturing communities, a value that aligns with academic knowledge and OA publishing.

The cooperative framework facilitates power sharing by untangling hierarchies and information flows. Every worker or member - which for publishing might include, though is not limited to, authors, reviewers, designers, developers, governance facilitators, and editors - would collaborate as unalienated co-owners of the venture. The coop model supports equitable compensation and participation in decision making processes. Transparency would be critical to the facilitation of these processes, which would further advance the goals of a publisher working to be open and accessible.

While cooperatives can subsist within a capitalist context, they can also challenge its underlying assumptions by redefining value. The cooperative provides additional vocabulary for the multivalent value of knowledges. We also know that for too long we have prioritised certain forms, regions, languages to the detriment of all knowledges. Both a cooperative organization and labor to share knowledge assert that the more we work together, the greater our opportunity to thrive. The work of publishing cooperatives can shift public discourse and funding streams toward a more expansive view of value.

\section{Creating infrastructure for publishing coops}

To encourage the development of cooperatives for the publishing industry, we imagine the following possibilities. First, as cooperatives encourage the breaking of silos, we seek out adjacent industries that can conspire with scholarly publishing, such as the arts and education. Both social and technical infrastructure must be crafted to reenvision communication to replace hierarchical decision making and adopt values of co- 
operation, co-ownership, and co-production. By encouraging transparency and new collaborations, we can eschew prescriptive modes of being and imagine, as the Zapatistas have asserted, 'a world where many worlds fit.'

If we are to create a cooperative for the development of cooperatives, infrastructure might include a hub for sharing and discussing information and ideas to develop the tools and practices for new forms of OA publishing. Such an organization would strive for community where people can meet, exchange ideas, find collaborators, resources, co-create values and experiment - a critical space without a box for people to think inside or outside of where radical un-hierarchical projects can come to life. By rethinking transaction and exchange, we would embark upon a network of collaborators that can help promote and support the development of each other's initiatives, for example through the exchange of available skills and resources. Our aim is to develop an open and accessible space where we might exchange knowledge on those practices and procedures to better facilitate the exchange of knowledge. If you would like to participate in these initiatives, we welcome you to join us at The New Cooperative.

If the trajectory of scholarly publishing is truly to become open and accessible, it must counter institutional academia's trends toward precarity and alienation. Cooperatives provide a plausible structure to support more people and revitalize the industry of scholarship by asserting our interdependence. We are called to operate on the belief that our resources are not scarce, nor that this can only be a meaningful career for the lucky few. We know the magnitude and worth of our work, and the amount of human effort required. So hire everyone, share ownership and solidarity to not simply sustain but generate scholarly publishing.

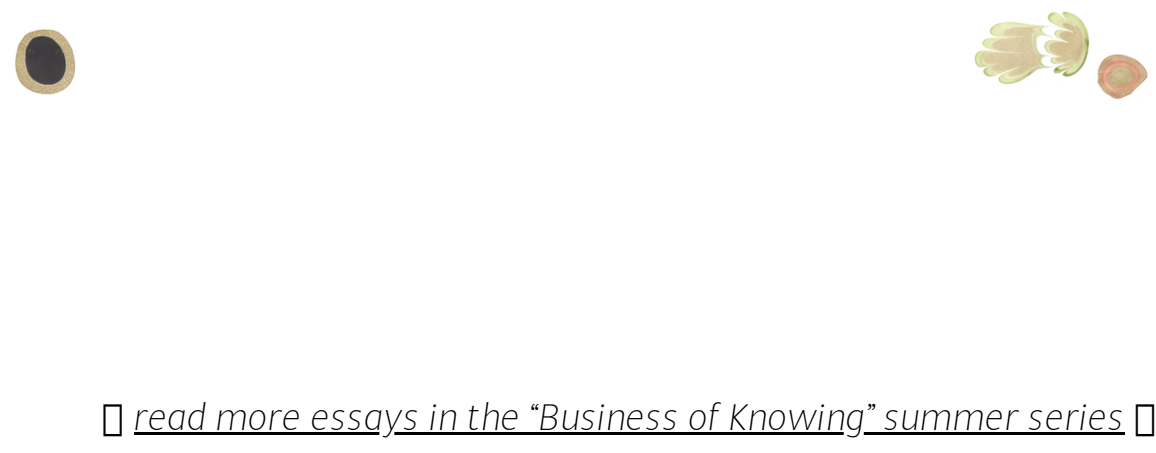

\section{Footnotes}

1. Knowledge(s)' is used in plural following decolonial writers like Sousa Santos. $\bullet$ 